
\title{
PReserch Square \\ Is 99mTechnetium Pertechnetate Thyroid Uptake accurate in Thyrotoxicosis Evaluation?
}

\author{
kusai al-muqbel ( $\nabla$ kusai10@hotmail.com ) \\ Reema Tashtoush \\ Irbid private endocrinology clinic

\section{Fadia Mayyas} \\ Jordan University of Science and Technology \\ Wael Marashdeh \\ Jordan University of Science and Technology \\ Amr Tashtoush \\ king abdullah university hospital \\ Raya AbuGhanmi \\ king abdullah university hospital \\ Ali Abdel Kareem \\ king abdullah university hospital
}

Jordan University of Science and Technology https://orcid.org/0000-0002-9334-2100

\section{Research article}

Keywords: Thyroid, Uptake, 99mTc, radioiodine, thyrotoxicosis

Posted Date: June 22nd, 2020

DOI: https://doi.org/10.21203/rs.3.rs-34343/v1

License: (c) (i) This work is licensed under a Creative Commons Attribution 4.0 International License.

Read Full License 


\section{Abstract}

\section{Background}

This study aimed to evaluate the $99 \mathrm{mTc}$ thyroid uptake (TcTU) in terms of (1) normal mean and range, (2) level of uncertainty in thyrotoxic patients and (3) effectiveness of adding radioiodine uptake in patients with uncertain TcTU values.

\section{Methods}

Patients referred for TcTU test were included and categorized into groups: euthyroid, Graves' disease, toxic nodular goiter and subacute thyroiditis. Mean and range of TcTU were obtained separately for each group. Second radioiodine uptake test was performed in patients who had uncertain TcTU (overlap with normal range).

\section{Results}

209 patients were included (54 euthyroid, 112 Graves' disease, 29 toxic nodules and 17 subacute thyroiditis patients). Normal mean and range of TcTU were $1.5+/-1.1 \%$ and $0.17-4.8 \%$, respectively. Mean TCTU was high in hyperthyroid patients and was extremely low in subacute thyroiditis patients, however, uncertain values was noted in about $30 \%$ of the patients. TcTU was uncertain in 39 hyperthyroid patients and in 10 subacute thyroiditis patients, while second radioiodine uptake was high in the former and extremely low in the latter.

Test sensitivity was $68 \%$, specificity was $100 \%$, positive predictive value (PPV) was $100 \%$, negative predictive value (NPV) was $52 \%$ and accuracy was $76 \%$.

\section{Conclusion}

TCTU major disadvantage is the uncertainty seen in third of patients degrading test sensitivity and accuracy. We managed to overcome this uncertainty by adding second radioiodine thyroid uptake test. Accordingly, single visit TcTU was accurate and sufficient in about two thirds of patients while the remainder required second radioiodine uptake to reach accurate diagnosis.

\section{Background}

Thyrotoxicosis is a common endocrine medical problem manifested clinically by several non-specific symptoms (including but not limited to tremor, palpitation, excessive sweating, weight loss, diarrhea, nervousness... etc.) and confirmed biochemically by thyroid function text (TFT). Biochemically, thyrotoxic patient has suppressed thyroid stimulating hormone (TSH) with elevated thyroid hormones (T3 and T4). Thyroid scan and uptake is the test of choice for thyroid function evaluation that could discriminate between causes of thyrotoxicosis. Causes of thyrotoxicosis include subacute thyroiditis, Graves' disease and toxic nodular goiter $(1,2)$. Technetium- $99 \mathrm{~m}(99 \mathrm{mTc})$ pertechnetate is becoming radiotracer of choice 
in thyroid uptake evaluation owing to its low cost, ready availability, rapid single visit imaging, lower radiation burden to the patient and good image quality (1). lodine-123 (123I) is expensive and requires a return visit by the patient next day (1). lodine-131 (131I) has high radiation burden on the patients so it is abandoned in developed countries (2).

However, reported major disadvantages of $99 \mathrm{mTc}$ thyroid uptake are narrow normal uptake range of 0.5$4 \%$ and overlap between normal range and ranges of thyrotoxic patients $(3,4)$. Accordingly, some endocrinologists and some nuclear physicians agree on conducting $99 \mathrm{mTc}$ thyroid uptake but with some level of uncertainty about the results.

This study aimed to evaluate the $99 \mathrm{mTc}$ thyroid uptake in terms of (1) normal mean and range in our euthyroid patients, (2) level of uncertainty in thyrotoxic patients and (3) effectiveness of adding radioiodine uptake in patients with uncertain $99 \mathrm{mTc}$ uptake values.

\section{Methods}

Patients included in this study were those referred to our nuclear medicine department for thyroid scan and uptake. The study started in March 2016 and ended in April 2018. The study was approved by Jordan University of Science and Technology institutional review board (IRB). Consents were waived according to hospital policy. Patients were referred for investigation of thyrotoxicosis confirmed biochemically by TFT test. However, some euthyroid patients (normal TFT) were also referred and included in the study. Main reasons for euthyroid patient referral were thyroid nodule evaluation and thyrotoxic symptoms as well as borderline TFT (low normal TSH). All patients underwent $99 \mathrm{mTc}$ thyroid scan and uptake. Normal $99 \mathrm{mTc}$ uptake reference range in our department is $0.4-4 \%$ according to data published by Atkin (3). Second thyroid uptake test utilizing radioiodine was performed in thyrotoxic patients who had uncertain $99 \mathrm{mTc}$ uptake that was within the normal reference range. Our local mean reference range of radioiodine 131 l thyroid uptake is $15 \%+/-7 \%$ according to our previously published data (2). Based on image findings and uptake value, patients were categorized into the following groups: normal, Graves' disease, toxic nodular goiter (single or multiple) and subacute thyroiditis. Mean and range of $99 \mathrm{mTc}$ thyroid uptake were obtained separately in the following groups: euthyroid patients, Graves' disease patients, Toxic nodular patients and subacute thyroiditis patients. As far as patients who underwent second thyroid uptake test utilizing radioiodine 131; mean and range of radioiodine 131। thyroid uptake were also obtained for same groups.

Clinically, all thyrotoxic patients included in this study were followed up by endocrinology clinics and treated according to diagnosis. We looked up the type of treatment and range of follow up for each group to validate the diagnosis obtained by thyroid scan and uptake.

\section{Statistics:}

Sensitivity, specificity, positive predicative valve (PPV) and negative predicative value (NPV) for $99 \mathrm{mTc}$ thyroid uptake in thyrotoxicosis were calculated. Moreover; accuracy of $99 \mathrm{mTc}$ thyroid uptake in 


\section{Technique:}

\section{9mTc Scintiscan:}

30 minutes after intravenous administration of $18.5-\mathrm{MBq}(5 \mathrm{mCi}) 99 \mathrm{mTc}$ pertechnetate, 5 minutes static thyroid images were obtained in anterior, right anterior oblique and left anterior oblique views while the patient is supine with extended neck. Images were obtained by a large-field-of-view gamma camera (Mediso, Anyscan, Budapest, Hungary) fitted with low energy all-purpose parallel hole collimator. Image data were recorded on a $128 \times 128$ computer matrix.

\section{9mTc Thyroid uptake measurement:}

$99 \mathrm{mTc}$ thyroid uptake was obtained utilizing MEDISO thyroid uptake software. Data required by the software are: injected dose measured by $\mathrm{MBq}$ in the syringe and time of measurement, syringe residual dose measured by $\mathrm{MBq}$ and time of measurement, thyroid region of interest (ROI) and neck background $\mathrm{ROI}$.

\section{Measurement of 24-hour radioiodine Thyroid uptake:}

24 hours after oral administration of an average of $1.85 \mathrm{MBq}$ (50 microCi) 1131 capsule, uptake was measured with a thyroid probe (Biodex medical systems, Atomlab 950, CA, USA). Patients were seated facing the detector which was positioned $25 \mathrm{~cm}$ from the anterior surface of the patient's neck at the level of the cricoid. Patient's thigh count is obtained for 1 minute. The administered capsule is placed $25 \mathrm{~cm}$ from the detector and counted for one minute just before administration. Phantom was used. The radioiodine uptake (RIU) is calculated using the following relationship:

RIU = neck counts (cpm) - thigh counts (cpm)/administered counts (cpm) - background counts (cpm) $\mathrm{x}$ $100 \%$.

\section{Results}

Patient group characteristics are summarized in Table 1. Two-hundred and nine patients were included in our study. About $72 \%$ of the patients were females and $28 \%$ were males. Most patients were middle aged with average $( \pm S D)$ of $43( \pm 15)$ y and range of 7-81 y. Thyrotoxic patients had suppressed TSH and elevated T3 and T4 hormones as shown in Table 2. All patients underwent $99 \mathrm{mTc}$ thyroid scan and uptake, whereas only 60 patients had combined $99 \mathrm{mTc} /$ radioiodine thyroid uptake because of uncertain $99 \mathrm{mTc}$ uptake values. 
Table 1

showing number, age and gender of patients who underwent $99 \mathrm{mTc}$ thyroid scan and uptake. Patients are classified as normal (euthyroid), hyperthyroid (Graves' disease or toxic nodules) or subacute thyroiditis.

\begin{tabular}{|c|c|c|c|c|c|c|c|c|c|}
\hline & \multicolumn{2}{|c|}{ Normal (Euthyroid) } & \multicolumn{2}{|c|}{ Graves' Disease } & \multicolumn{2}{|c|}{ Toxic Nodules } & \multicolumn{2}{|c|}{$\begin{array}{l}\text { Subacute } \\
\text { Thyroiditis }\end{array}$} & \multirow[t]{2}{*}{ Total } \\
\hline & No & Age $(Y)$ & No. & Age $(\mathrm{Y})$ & No. & Age $(Y)$ & No. & Age $(Y)$ & \\
\hline & $\mathrm{F}: \mathrm{M}$ & Range & $\mathrm{F}: \mathrm{M}$ & Range & $\mathrm{F}: \mathrm{M}$ & Range & $\mathrm{F}: \mathrm{M}$ & Range & \\
\hline & & $\begin{array}{l}\text { (mean +/- } \\
\text { SD) }\end{array}$ & & $\begin{array}{l}\text { (mean +/- } \\
\text { SD) }\end{array}$ & & $\begin{array}{l}\text { (mean } \\
+/-S D)\end{array}$ & & $\begin{array}{l}\text { (mean } \\
+/-S D)\end{array}$ & \\
\hline \multirow[t]{2}{*}{$99 \mathrm{mTc}$} & 54 & $7-78$ & 112 & $15-72$ & 26 & $20-81$ & 17 & $22-73$ & 209 \\
\hline & $38: 16$ & $(44+/-16)$ & $79: 33$ & $\begin{array}{l}(40+/- \\
13)\end{array}$ & $20: 6$ & $\begin{array}{l}(46 \\
+/-15)\end{array}$ & $14: 3$ & $\begin{array}{l}(39+/- \\
15)\end{array}$ & \\
\hline
\end{tabular}

Table 2

showing thyroid function test results in patient groups. Local laboratory normal reference range for thyroid function test is also included.

\begin{tabular}{|llllll|}
\hline & $\begin{array}{l}\text { Normal } \\
\text { (Euthyroid) }\end{array}$ & $\begin{array}{l}\text { Graves' } \\
\text { Disease }\end{array}$ & $\begin{array}{l}\text { Toxic } \\
\text { Nodules }\end{array}$ & $\begin{array}{l}\text { Subacute } \\
\text { Thyroiditis }\end{array}$ & $\begin{array}{l}\text { Reference } \\
\text { Range }\end{array}$ \\
\hline $\mathrm{TSH}$ & $1.9+/-1.2$ & $0.011+/-0.017$ & $\begin{array}{l}0.025+/- \\
0.33\end{array}$ & $0.019+/-0.016$ & $0.27-4.64$ \\
$\mathrm{mIU} / \mathrm{L}$ & & & $27+/-12$ & $33+/-22$ & $12-22$ \\
$\mathrm{~T} 4$ & $16+/-6.5$ & $49+/-37$ & & & \\
$\mathrm{pmol} / \mathrm{L}$ & & & $10+/-5$ & $9+/-4$ & $3.1-6.8$ \\
$\mathrm{T3}$ & $5+/-1.6$ & $19+/-13$ & & & \\
$\mathrm{pmol} / \mathrm{L}$ & & & & & \\
\hline
\end{tabular}

Figure 1 shows mean and range of $99 \mathrm{mTc}$ thyroid uptake for euthyroid and thyrotoxic patient groups. Normal mean and range of $99 \mathrm{mTc}$ uptake were $1.5+/-1.1 \%$ and $0.17-4.8 \%$, respectively. Mean $99 \mathrm{mTc}$ uptake is markedly high in hyperthyroid patients and extremely low in subacute thyroiditis patients, but there is an overlap between ranges of thyrotoxic patient groups and normal individuals (euthyroid) as noted in Fig. 1. Table 3 and Figs. 2-3 show that $99 \mathrm{mTc}$ uptake was uncertain (overlap with normal range) in 39 hyperthyroid patients while radioiodine uptake was high in all of them. Eleven euthyroid patients underwent both Tc99m and radioiodine uptake which was normal in both radiotracers (Fig. 4). 
Table 3

showing mean and range 131/ thyroid uptake in hyperthyroid (Graves' disease or toxic nodules) group and subacute thyroiditis group who have uncertain $99 \mathrm{mTc}$ uptake (overlap with normal range) as well as in 11 euthyroid patients.

\begin{tabular}{|c|c|c|c|c|c|c|c|c|}
\hline \multirow[t]{4}{*}{ Radiotracer } & \multicolumn{2}{|c|}{ Normal (Euthyroid) } & \multicolumn{2}{|c|}{ Graves' Disease } & \multicolumn{2}{|c|}{ Toxic Nodules } & \multicolumn{2}{|c|}{$\begin{array}{l}\text { Subacute } \\
\text { Thyroiditis }\end{array}$} \\
\hline & \multirow[t]{3}{*}{ no. } & Uptake\% & no. & Uptake\% & no. & Uptake\% & no. & Uptake\% \\
\hline & & Range & & Range & & Range & & Range \\
\hline & & $\begin{array}{l}\text { (mean +/- } \\
\text { SD) }\end{array}$ & & $\begin{array}{l}\text { (mean +/- } \\
\text { SD) }\end{array}$ & & $\begin{array}{l}\text { (mean +/- } \\
\text { SD) }\end{array}$ & & $\begin{array}{l}\text { (mean +/- } \\
\text { SD) }\end{array}$ \\
\hline \multirow[t]{2}{*}{$131 ।$} & \multirow[t]{4}{*}{11} & $5-17$ & 28 & $20-61$ & 11 & $20-38$ & 10 & $0.2-5.1$ \\
\hline & & $(12+/-4)$ & & $(35+/-10)$ & & $(28+/-6)$ & & $(1.9+/-1.5)$ \\
\hline \multirow[t]{2}{*}{$99 \mathrm{mTc}$} & & $0.2-4.9$ & & $0.43-3.5$ & & $0.6-3.6$ & & $0.1-0.7$ \\
\hline & & $(1.4+/-1)$ & & $(2+/-0.9)$ & & $(1.4+/-1)$ & & $(0.3+/-0.2)$ \\
\hline
\end{tabular}

Figure 1 shows that mean $99 \mathrm{mTc}$ thyroid uptake was extremely low $(<1 \%)$ in subacute thyroiditis patients. However, 10 out of 17 subacute thyroiditis patients had uncertain $99 \mathrm{mTc}$ thyroid uptake as uptake (overlap with normal range). Accordingly, those 10 patients underwent radioiodine thyroid uptake which was low (Table 3 and Fig. 5).

Hyperthyroid patients (Graves' disease and toxic nodules) were followed-up clinically for at least 6 months while subacute thyroiditis patients were followed-up clinically for at least 2 months (Table 4). Graves' disease patients and toxic nodules' patients were treated successfully by anti-thyroid medications and/or by radioiodine ablation. Most patients with subacute thyroiditis recovered within 2-3 months (Table 4). 
Table 4

showing follow up duration range, type of treatment and treatment outcome in each patient group.

Follow-up Anti-thyroid $1131 \quad$ Outcome $\quad$ Total

Duration Treatment Ablation ( $n$ ) Hypothyroid Recovery (n)

$\begin{array}{llll}(\mathrm{mo}) & (\mathrm{n}) & \text { (n) }\end{array}$

$\begin{array}{lllllll}\text { Euthyroid } & - & - & - & - & - & 54 \\ \text { Graves } & 6-30 & 107 & 65^{\star} & 65 & 47 & 112 \\ \text { Disease } & & & & & & \end{array}$

$\begin{array}{lllllll}\text { Toxic Nodules } & 6-24 & 4 & 22 & 5 & 21 & 26 \\ \text { Subacute } & 2-6 & 0 & 0 & 3 & 14 & 17\end{array}$

Thyroiditis

*Sixty patients failed anti-thyroid treatment for 1-1.5 year duration and referred for radioiodine ablation. The remainder 5 patients immediately underwent radioiodine ablation.

Sensitivity, specificity, PPV, NPV and accuracy of $99 \mathrm{mTc}$ thyroid uptake in thyrotoxicosis were as follow: sensitivity was $68 \%$, specificity was $100 \%$, PPV was $100 \%$, NPV was $52 \%$ and accuracy was $76 \%$.

\section{Discussion}

Thyroid uptake value along with thyroid scintigraphic features provides useful information on the etiology of thyrotoxicosis. Reduced uptake value with poor visualization of thyroid gland is often associated with subacute thyroiditis whereas elevated uptake value with diffusely enlarged thyroid or focal nodules is often seen in patients with Graves' disease or toxic nodular goiter $(1,2)$.

$99 \mathrm{mTc}$ pertechnetate is becoming the radiotracer of choice in thyroid uptake evaluation owing to its low cost, ready availability, rapid single visit imaging, lower radiation burden to the patient and good image quality (1).

Although $99 \mathrm{mTc}$ does not undergo organification by follicular cells like iodine; thyroid uptake of $99 \mathrm{mTc}$ pertechnetate is closely correlated with radioiodine uptake in thyrotoxic patients (5). lodine-123 (123I) provides good image quality and low radiation burden to the patient. However, $123 \mathrm{I}$ is expensive and not readily available as well as test is requiring a return visit by the patient next day (1). lodine-131(131I) is abandoned in Europe and North America because of its high radiation burden on patients secondary to long half-life and beta radiation (2).

In the present study, normal range of $99 \mathrm{mTc}$ thyroid uptake was $0.17-4.8 \%$ and normal mean was $1.5+/$ $1.1 \%$. Our results are very close to previously published results. In 1971, Atkin reported normal mean of $1.73+/-0.85 \%$ and normal range of $0.5-4 \%$ (3). A normal range of $0.4-2.5 \%$ was reported in another 
study (6). One more study reported normal mean of $0.9 \%$ and normal range of $0.1-6.3 \%(1)$. In contrary, one study reported a narrower normal range of $0.4-1.7 \%(7)$.

Despite all advantages of $99 \mathrm{mTc}$ thyroid uptake, overlap between normal uptake range in euthyroid patients and uptake range of thyrotoxic patients is considered a major disadvantage. This disadvantage is even exaggerated because the normal range of $99 \mathrm{mTc}$ thyroid uptake is generally low and narrow as well as neck background activity is relatively high (8-9). In concordance with that; our data showed that $28 \%(39 / 138)$ of our hyperthyroid patients had uncertain values of $99 \mathrm{mTc}$ thyroid uptake (overlap with normal range). Moreover, $59 \%$ (10/17) of subacute thyroiditis patients in our study had uncertain $99 \mathrm{mTc}$ thyroid uptake values (overlap with lower end of normal range). It has been reported that 8 out of 26 (31\%) thyrotoxic patients had normal 99mTc thyroid uptake (4). In another study, 24 out of 201 (12\%) Graves' disease patients had normal 99mTc uptake (6). In addition, it was found that $99 \mathrm{mTc}$ thyroid uptake in 57 Graves' disease patients ranged from $0.97 \%-40.1 \%(10)$.

In order to overcome disadvantages of $99 \mathrm{mTc}$ thyroid uptake; we added second thyroid uptake test utilizing radioiodine for thyrotoxic patients who had uncertain $99 \mathrm{mTc}$ uptake values (overlap with normal range). Radioiodine uptake was high in all $28 \%$ of hyperthyroid patients with uncertain $99 \mathrm{mTc}$ uptake value. As well; radioiodine uptake was low in 11 subacute thyroiditis patients with uncertain $99 \mathrm{mTc}$ uptake value.

To confirm the results of thyroid uptake test in our patients we reviewed the medical records of our patients. All patients diagnosed with Graves' disease or toxic nodules by $99 \mathrm{mTc}$ alone or by $99 \mathrm{mTc} /$ radioiodine were treated by anti-thyroid medications and/or radioiodine ablation. Outcome in those patients was good (recovery or hypothyroidism) reflecting that our approach succeeded in overcoming the uncertainty of $99 \mathrm{mTc}$ in thyrotoxicosis evaluation. Similarly, we noted good outcome in patients diagnosed to have subacute thyroiditis by this approach. Most of them recovered spontaneously and few of them became hypothyroid.

Statistically, $99 \mathrm{mTc}$ thyroid scan is found to be specific in thyrotoxicosis evaluation. However, uncertain values of this test degraded sensitivity and accuracy of the test which were found to be $68 \%$ and $76 \%$ respectively. Adding second radioiodine uptake test to uncertain cases managed to overcome this disadvantage. In another word, third of thyrotoxic patients are expected to have uncertain $99 \mathrm{mTc}$ thyroid uptake values overlapping with normal range. By combining radioiodine thyroid uptake to $99 \mathrm{mTc}$ uptake in this circumstance, we could reach accurate diagnosis in those patients. Two thirds of thyrotoxic patients will gain advantages of $99 \mathrm{mTc}$ thyroid uptake i.e single visit test, good image quality and low radiation burden (1). This approach is found very helpful in our department as radioiodine $131 \mathrm{l}$ is available for imaging not radioiodine 123I which is expensive and of relative short half-life. By this approach, we managed to abandon radioiodine $131 \mathrm{I}$ from 2 thirds of our patients and the same time we continued to have accurate diagnosis in all patients. We believe that this approach is helpful in most developing countries where radioiodine 123 I is not readily available. 
We admit that third of our patients who underwent combined $99 \mathrm{mTc} / 131 \mathrm{I}$ thyroid uptake received higher radiation dose. The dose to the thyroid from $131 \mathrm{I}$ is about 100 times greater than that from $123 \mathrm{I}$ for the same administered activity $(\approx 1 \mathrm{rad} / \mu \mathrm{Ci}[10 \mathrm{mGy} / 0.037 \mathrm{MBq}]$ versus $1 \mathrm{rad} / 100 \mu \mathrm{Ci}[10 \mathrm{mGy} / 3.7 \mathrm{MBq}])$. The absorbed thyroid dose from 99mTc-pertechnetate is about $1 \mathrm{rad} / 5000 \mu \mathrm{Ci}(10 \mathrm{mGy} / 185 \mathrm{MBq})$ (11). The average administered dose is $5 \mathrm{mCi}(185 \mathrm{MBq}) 99 \mathrm{mTc}$ which results in 1 rad radiation absorption to thyroid. This is a negligible radiation absorbed dose as compared to that resulting from radioiodine.

\section{Conclusion}

This study showed that $99 \mathrm{mTc}$ thyroid uptake is the test of choice for evaluation of thyrotoxic patients for several reasons; the most important is being performed in single visit. Second important reason is that we managed to abandon 131 I radioiodine from thyroid imaging as 123 I radioiodine is not available in our country which is true for most developing countries. However, its major disadvantage is the uncertainty as third of our patients had uncertain thyroid uptake values overlapping with normal range. This uncertainty degraded test sensitivity and accuracy. We managed to overcome this uncertainty by adding second radioiodine thyroid uptake test in patients with uncertain $99 \mathrm{mTc}$ thyroid uptake. According to this approach, single visit $99 \mathrm{mTc}$ thyroid uptake was accurate and sufficient in about two thirds of our thyrotoxic patients while the remainder third of our patients with uncertain $99 \mathrm{mTc}$ thyroid uptake values required additional 2-day visit radioiodine thyroid uptake to reach accurate diagnosis.

\section{Abbreviations}

TCTU

$99 \mathrm{mTc}$ thyroid uptake

TFT

thyroid function text

TSH

stimulating hormone

$99 \mathrm{mTc}$

Technetium-99m

123I

lodine-123

1311

lodine-131

PPV

positive predicative valve

NPV

negative predicative value

RIU

radioiodine uptake 
Cpm

counts per minute

\section{Declarations}

- Ethics approval and consent to participate: The study was approved by Jordan University of Science and Technology institutional review board (IRB) headed by Dr Yosuf Khader ( phone \# 962796802040). Consents were waived according to hospital policy.

- Consent to publish: not applicable

- Availability of data and materials: The datasets used and/or analyzed during the current study are available from the corresponding authors on reasonable request

- Competing interests: authors have no conflict of interest to declare

- Funding: this work did not receive any kind of funding

\section{- Authors' Contributions:}

\section{KA}

Methodology introduction, reading scan and uptake and writing the paper

\section{RT}

Patient referral and clinical diagnosis and follow up

\section{FM}

As a radiopharmacist, she prepared doses and validated uptake values

\section{WM}

Read scan and uptake and participated in writing discussion
AT
Data collection and clinical follow up

\section{RA}
Data collection and clinical follow up
AA
Data collection and clinical follow up 
$\star \star \star$ Please note that all authors have read and approved the manuscript

\section{- Acknowledgements: not applicable}

\section{References}

1. Macauley M, Shawgi M, Ali T, Curry A, Howe K, Howell E, et al. Assessment of normal reference values for thyroid uptake of technetium-99m pertechnetate in a single centre UK population. Nucl Med Commun. 2018;39:834-8.

2. Al-Muqbel KM, Tashtoush RM. Patterns of thyroid radioiodine uptake: Jordanian experience. J Nucl Med Technol. 2010;38:32-6.

3. Atkins HL. Technetium-99m pertechnetate uptake and scanning in the evaluation of thyroid function. Semin Nucl Med. 1971;1:345-55.

4. Sucupira MS, Camargo EE, Nickoloff EL, Alderson PO, Wagner HN Jr. The role of 99mTc pertechnetate uptake in the evaluation of thyroid function. Int J Nucl Med Biol. 1983;10:29-33.

5. Uchida T, Suzuki R, Kasai T, Onose H, Komiya K, Goto H, et al. Cutoff value of thyroid uptake of ( 99 m)Tc-pertechnetate to discriminate between Graves' disease and painless thyroiditis: a single center retrospective study. Endocr J. 2016;63:143-9.

6. Ikekubo K, Hino M, Ito H, Koh T, Ishihara T, Kurahachi H, et al. Thyrotoxic Graves' disease with normal thyroidal technetium-99m pertechnetate uptake. Ann Nucl Med. 1990;4:43-8.

7. Ramos CD, Zantut Wittmann DE, Etchebehere EC, Tambascia MA, Silva CA, Camargo EE. Thyroid uptake and scintigraphy using $99 \mathrm{mTc}$ pertechnetate: standardization in normal individuals. Sao Paulo Med J. 2002;120:45-8.

8. Maisey MN, Natarajan TK, Hurley PJ, Wagner HN Jr. Validation of a rapid computerized method of measuring $99 \mathrm{mTc}$ pertechnetate uptake for routine assessment of thyroid structure and function. $\mathrm{J}$ Clin Endocrinol Metab. 1973;36:317-22.

9. Schneider PB. Simple, rapid thyroid function testing with $99 \mathrm{mTc}$ pertechnetate thyroid uptake ratio and neck/thigh ratio. AJR Am J Roentgenol. 1979;132:249-53.

10. Kidokoro-Kunii Y, Emoto N, Cho K, Oikawa S. Analysis of the factors associated with Tc-99m pertechnetate uptake in thyrotoxicosis and graves' disease. J Nippon Med Sch. 2006;73:10-7.

11. Fred A, Mettler, Jr, Milton J Guiberteau. Essentials of Nuclear Medicine Imaging. 6th ed. Saunders; 2012.

\section{Figures}




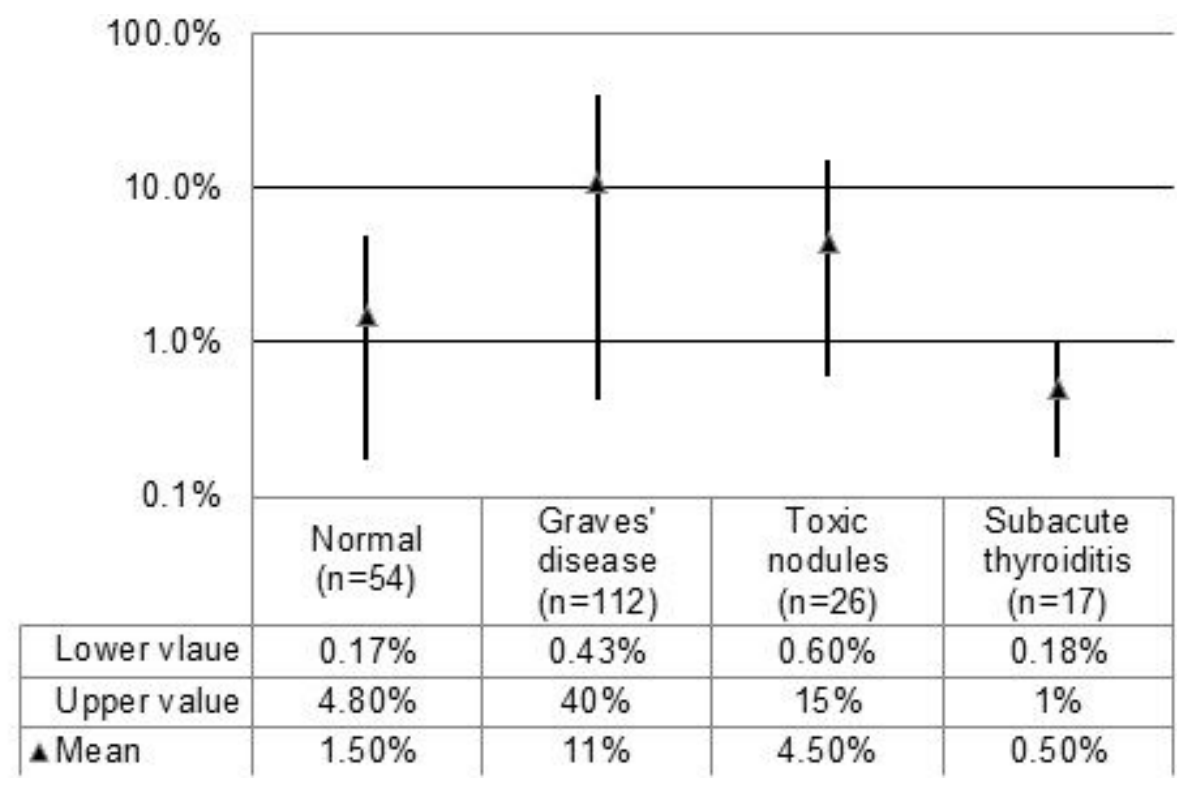

\section{Figure 1}

Mean and range of $99 \mathrm{mTc}$ thyroid uptake in euthyroid (normal) group and thyrotoxic groups including Graves' disease, toxic nodular goiter and subacute thyroiditis. Overlap is demonstrated between euthyroid (normal) group and thyrotoxic groups. Standard deviation (SD) values for patient groups are as follows: normal $=1.1$, Graves' disease $=10$, toxic nodules $=4$ and subacute thyroiditis $=0.4 . n=$ number. $Y$ axis is a logarithmic scale for the base 10. 

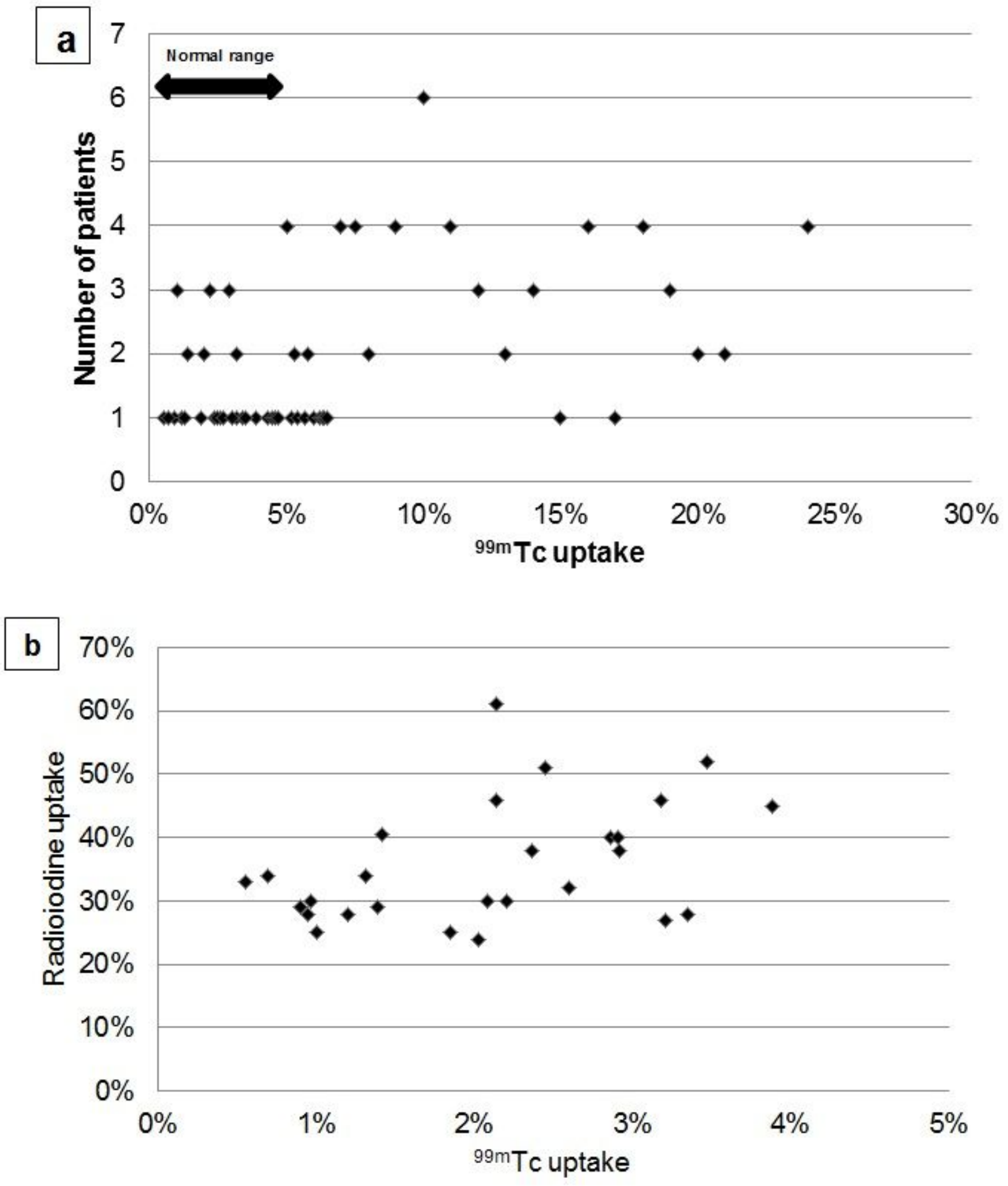

Figure 2

A- scatter of $99 \mathrm{mTc}$ thyroid uptake values in Graves' disease group (54 patients). B-Scatter of 131/ thyroid uptake values in 28 Graves' disease patients who have uncertain $99 \mathrm{mTc}$ uptake values (overlap with normal range). 

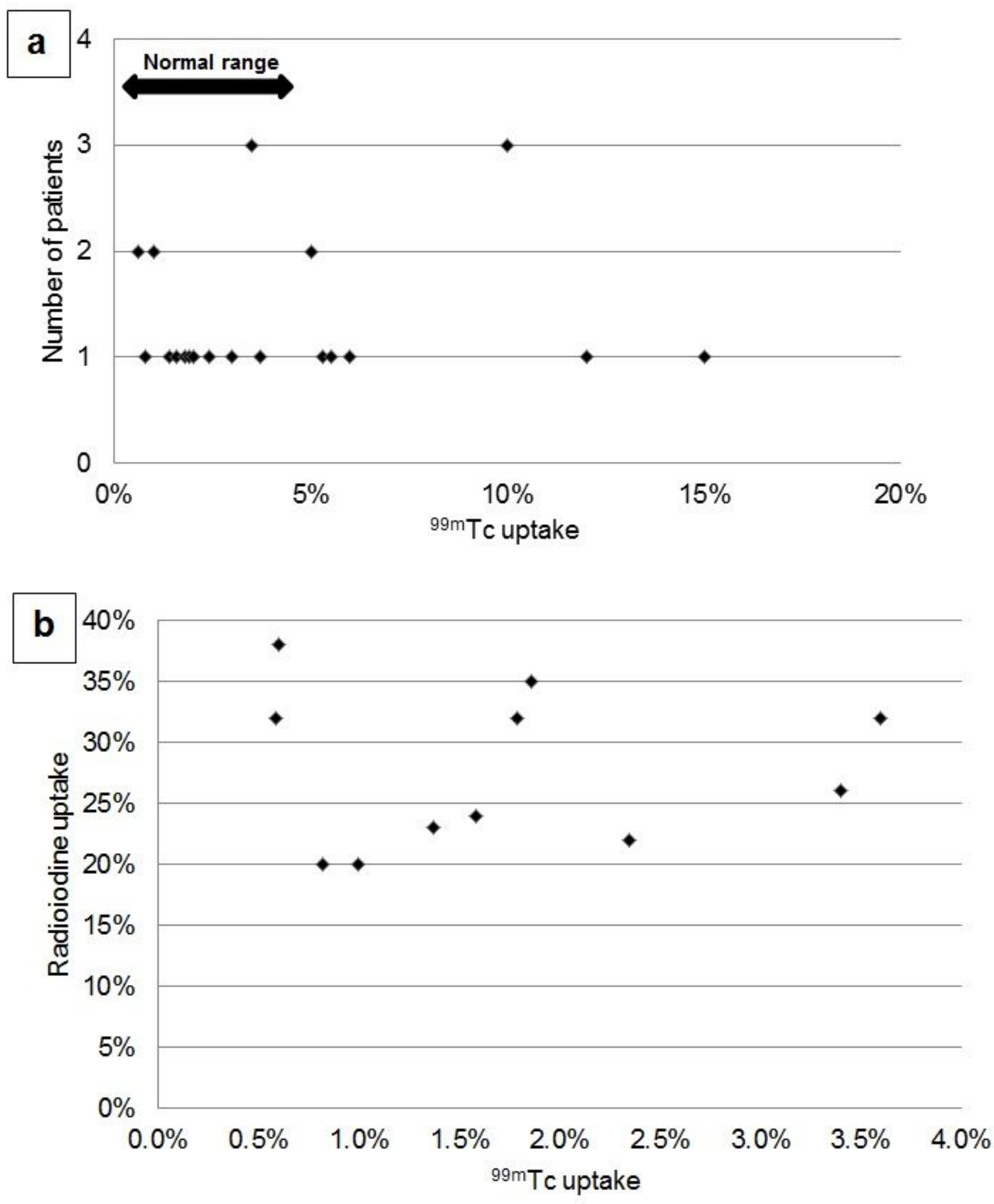

Figure 3

A- scatter of $99 \mathrm{mTc}$ thyroid uptake values in toxic nodules group (26 patients). B-Scatter of 131 I thyroid uptake values in 11 toxic nodules patients who have uncertain $99 \mathrm{mTc}$ uptake values (overlap with normal range). 

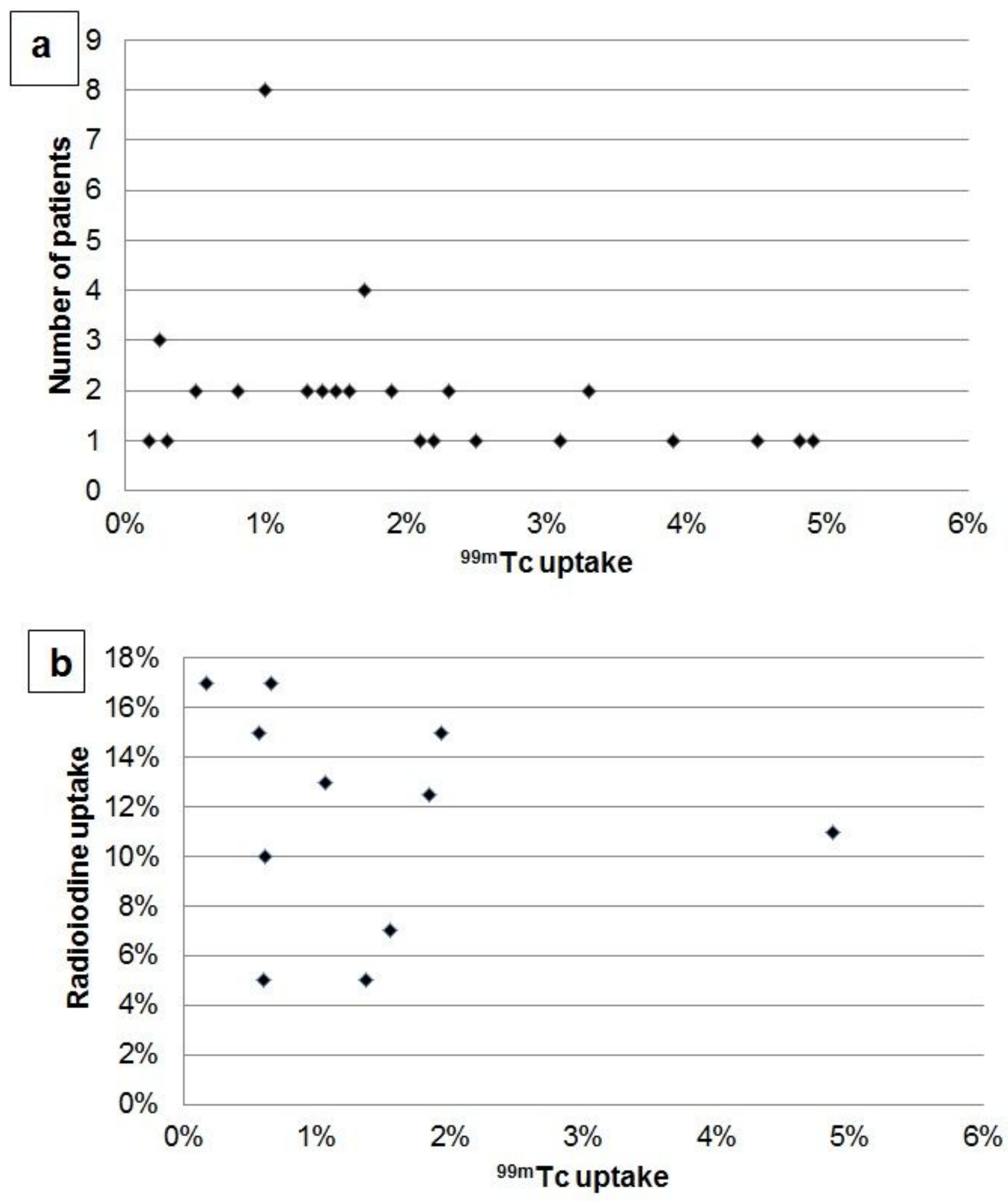

Figure 4

A- scatter of $99 \mathrm{mTc}$ thyroid uptake values in euthyroid (normal) group (54 patients). B-Scatter of 131 I thyroid uptake values in 11 euthyroid (normal) patients plotted against their $99 \mathrm{mTc}$ uptake values. 

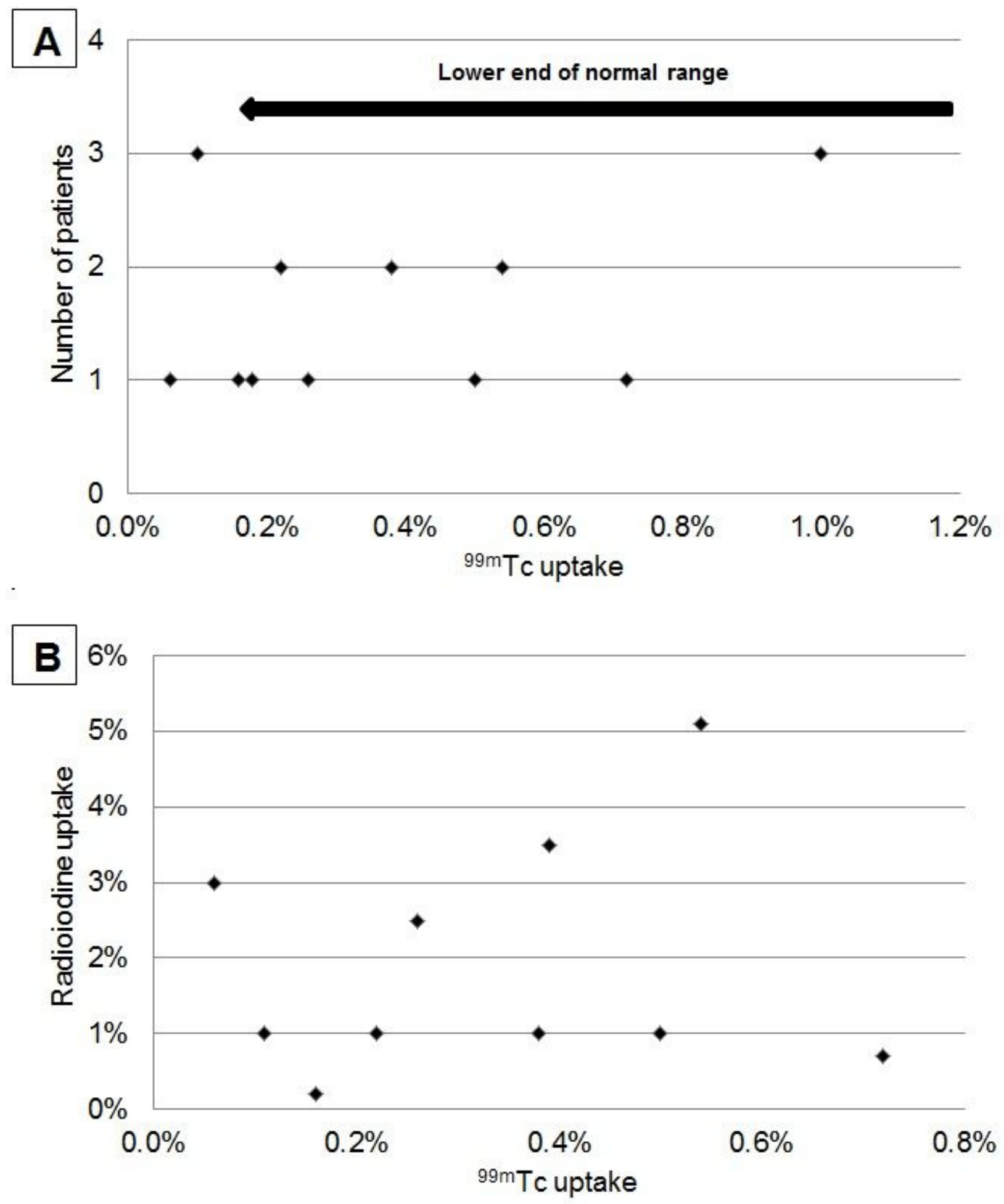

Figure 5

A- scatter of $99 \mathrm{mTc}$ thyroid uptake values in subacute thyroiditis group (17 patients). B-Scatter of 131 I thyroid uptake values in 10 subacute thyroiditis patients who have uncertain $99 \mathrm{mTc}$ uptake values (overlap with normal range).

\section{Supplementary Files}


This is a list of supplementary files associated with this preprint. Click to download.

- response.docx 